\title{
Male reproductive tactics to increase paternity in the polygynandrous Columbian ground squirrel (Urocitellus columbianus)
}

\author{
Shirley Raveh • Dik Heg • Vincent A. Viblanc • \\ David W. Coltman • Jamieson C. Gorrell • \\ F. Stephen Dobson • Adele Balmer • Peter Neuhaus
}

Received: 27 February 2010 /Revised: 15 August 2010 / Accepted: 4 October 2010 /Published online: 22 October 2010

(C) Springer-Verlag 2010

\begin{abstract}
In polyandrous and polygynandrous species where females mate with multiple partners, males are expected to maximize their fitness by exhibiting an array of reproductive behaviors to ensure fertilization success, such as competing for the best mating order within a mating sequence, optimizing their investment in copulation, and mate guarding. Though there is genetic evidence of a first-male precedence in siring success for many mammalian species, the causes of this effect are poorly understood. We studied influences on first-male precedence in Columbian ground squirrels (Urocitellus columbianus). We found that the time a male spent consorting and mate guarding declined with his mating order (both the
\end{abstract}

Communicated by A. Schulte-Hostedde

S. Raveh $(\bowtie) \cdot$ P. Neuhaus

Department of Eco-Ethology, Institute of Biology,

University of Neuchâtel,

Rue Emile-Argand 11, Case postale 158,

2009 Neuchâtel, Switzerland

e-mail: shirleyraveh@hotmail.com

D. Heg

Department of Behavioural Ecology, University of Bern,

3032 Hinterkappelen, Switzerland

V. A. Viblanc

Départment Ecologie, Physiologie et Ethologie,

IPHC, UMR 7178, CNRS-UdS,

67087 Strasbourg Cedex 02, France

D. W. Coltman · J. C. Gorrell

Department of Biological Sciences, University of Alberta,

Edmonton, Alberta T6G 2E9, Canada

\section{F. S. Dobson}

Centre d'Ecologie Fonctionnelle et Evolutive,

Centre National de la Recherche Scientifique-UMR 5175,

1919, Route de Mende,

34293 Montpellier Cedex 5, France highest for the first male to mate). Mate guarding by the first male significantly reduced, but did not exclude, the number of additional males a female accepted. Later mating males reduced the time spent consorting, suggesting a perceived decreased chance of fertilization success. Consortship and mate guarding durations were positively related to the male's siring success and to each other, suggesting that males adjusted these behaviors strategically to increase their chances of fertilization success. Our results suggest that besides being the first male to consort, first-male sperm precedence is further enhanced through longer mating bouts and by suppressing the chances and/or efforts of later mating males.

F. S. Dobson • A. Balmer

Department of Biological Sciences, Auburn University,

331 Funchess Hall,

Auburn, AL 36849, USA

P. Neuhaus

Department of Biological Sciences, University of Calgary,

2500 University Drive, NW,

Calgary, Alberta T2N 1N4, Canada

Present Address:

S. Raveh

Konrad Lorenz Institute for Ethology,

Austrian Academy of Sciences,

Savoyenstr. 1a,

1160 Vienna, Austria 
Keywords Mating order $\cdot$ Multiple mating $\cdot$ Mate guarding $\cdot$ Paternity $\cdot$ Male reproductive success . Columbian ground squirrels

\section{Introduction}

Sexual selection on males and females has been shown to shape the evolution of reproductive strategies in animals (Birkhead and Møller 1998; Shuster and Wade 2003; Danchin et al. 2008; Oliveira et al. 2008). In systems in which individuals of one or both sexes mate with multiple partners, a conflict between the sexes over parentage is likely to arise. For instance, females may be selected to seek extra-pair mating partners offering good genes (Andersson 1994) or additional paternal care (Koenig and Dickinson 2004; Kohda et al. 2009), and males may be selected to ensure full paternity of the brood through mating plugs, mate guarding, and female harassment (Birkhead and Møller 1998).

In polyandrous and polygynandrous systems, where females mate with several males during a single period of sexual receptivity, sperm competition and cryptic female mate choice may influence male reproductive success, leading to differential fertilization and variation in male reproductive success within a litter (Parker 1982, 1984; Lindén and Moller 1989; Birkhead and Pizzari 2002; Kraaijeveld-Smit et al. 2002).

Facing sperm competition, males are expected to develop mating and post-copulatory strategies in order to ensure siring success and maximize their fitness. Hence, males may need to compete for the best position within the mating sequence (e.g., Raveh et al. 2010) and adapt their ejaculate size to the intensity of sperm competition (Birkhead and Møller 1998). Or alternatively, males may try to swamp, remove, or block rival sperm (using copulatory plugs, for instance Murie and McLean 1980; Koprowski 1992; Birkhead and Møller 1998). By increasing their investment in copulation (i.e., longer and more frequent mating bouts) and by mate guarding, males may decrease the likelihood of females mating with additional partners (Parker 1970; Dobson 1983; Birkhead and Møller 1998; Simmons 2001; Pizzari and Snook 2003; Linn et al. 2007).

First-male sperm precedence (i.e., the probability of siring more offspring in a litter when being first to mate) and multiple paternity have been well studied in the mammalian genera Urocitellus and Ictidomys. These rodent species are especially good models for the study of mating behavior because females exhibit a very brief receptive phase $(<12 \mathrm{~h})$ during the breeding season, during which they typically copulate with several males (Hanken and Sherman 1981; Schwagmeyer and Parker 1987; Murie 1995; Lacey et al. 1997). Several authors have investigated and reported the existence of sperm precedence in these taxa, including 13-lined ground squirrels, Ictidomys tridecemlineatus (Foltz and Schwagmeyer 1989; Schwagmeyer and Foltz 1990); Belding's ground squirrels, Urocitellus beldingi (Hanken and Sherman 1981; Sherman 1989); in Arctic ground squirrels, Urocitellus parryii (Lacey et al. 1997); Idaho ground squirrels, Urocitellus brunneus (Sherman 1989); and Columbian ground squirrels, Urocitellus columbianus (Raveh et al. 2010).

In this study, we investigated copulatory and postcopulatory behaviors in free-living male Columbian ground squirrels ( $U$. columbianus) to identify underlying mechanisms that facilitate first-male sperm precedence and variation in male siring success (see Raveh et al. 2010). Previous studies suggested that reproductive male Columbian ground squirrels invest both time and energy in postcopulatory behaviors such as mating calls (Manno et al. 2007) and mate guarding (Manno and Dobson 2008). Whether such behavioral mechanisms influence siring success, however, remains unknown.

Thus, we investigated whether first-male sperm precedence was related to consorting and mate guarding durations. We investigated whether sperm precedence might be linked to consortship duration, having positive but declining effects on male siring success through the female's mating sequence by focusing on (1) whether consortship duration decreases with increasing mating order, explaining variation in siring success irrespective of mating sequence, and (2) whether mate guarding reduces the number of male mating partners, particularly if the operational sex ratio (estrous females/males) is low.

\section{Materials and methods}

\section{Study area and species}

We studied Columbian ground squirrels (U. columbianus) in the Sheep River Provincial Park (Alberta, Canada, $110^{\circ} \mathrm{W}$, $50^{\circ} \mathrm{N}, 1,500 \mathrm{~m}$ a.s.1.) in the seasons 2005 to 2008 (beginning of April to the end of July). Five neighboring colonies (A, B, C, D, E) were monitored. Columbian ground squirrels are colonial, hibernating rodents that inhabit subalpine and alpine meadows of the northern regions of the Rocky Mountains. The active season is short and adult males are typically the first to emerge from hibernation around mid-April, followed by females a few days to a week later (Murie and Harris 1982; Dobson et al. 1992; Neuhaus 2000; Neuhaus and Pelletier 2001; Raveh et al. 2010).

Columbian ground squirrels were caught within the first 2 days of emergence from hibernation using live traps baited with peanut butter (national live traps, WI, USA; $15 \times 15 \times 48$ and $\left.13 \times 13 \times 40 \mathrm{~cm}^{3}\right)$. Adult males were trapped 
first, emerging from hibernation in mid-April (average 22.5 April \pm 9.6 SD, range 12 April-26 May, $N=71$ ), followed by adult females (29.0 April $\pm 6.6,11$ April-17 May, $N=154$ ), yearling males (7.4 May \pm 8.9 , 16 April-28 May, $N=58$ ), and yearling females (8.5 May $\pm 8.5,21$ April-30 May, $N=90$; see also Murie and Harris 1982; Raveh et al. 2010). Adult females mated on average 4.4 days after emergence from hibernation (adults 4.4 \pm 2.2 SD days, range 3-15, $N=134$; yearlings $7.0 \pm 2.7$ days, range $5-11, N=4$ ).

Animals were individually marked using numbered fingerling fish tags (National Band \& Tag Co. Monel \#1) attached to both ears and a unique dorsal mark of black hair dye for field observations (Clairol ${ }^{\circledR}$, Hydriance-black pearl no. 52). At first capture, we collected ear tissue from each individual for use in paternity analyses. Tissue was collected by using sterilized scissors to snip off the distal portion of one pinna per animal. Tissue samples were placed in $95 \%$ ethanol and stored at $3^{\circ} \mathrm{C}$ until analysis. Thereafter, animals were trapped at least once per week and weighed to the nearest $5 \mathrm{~g}$ using Pesola ${ }^{\circledR}$ spring scales. During spring emergence, however, females were trapped and checked daily until they had undergone estrus and mating, the degree of swelling and openness of the vulva being good indicators of the upcoming estrus (Murie 1995). Females have their estrus approximately 4 days after emergence from hibernation. Gestation lasts 24 days and females give birth to a litter averaging three (one to seven) naked and blind juveniles in a specially constructed nest burrow (Dobson and Murie 1987; Murie 1995). Weaned offspring emerge above ground some 27 days later (Murie and Harris 1982).

\section{Observations of consorting associations}

Focal observations of females in estrus were conducted from April to mid-May 2005, 2006, 2007, and 2008. Squirrels were observed at a distance using binoculars from the top of 2- to 3-m-high wooden stands dispersed throughout the meadows. Mating activity begins in the morning between 0700 and 1000 hours and lasts until 1400 to 1700 hours in the afternoon. Generally, a male followed a female into a burrow, but in some cases, the male either entered a burrow system with an estrous female already inside or had stayed overnight in the same burrow system with a pre-estrous female (A.P. Nesterova, S. Raveh, T.G. Manno, D.W. Coltman and F.S. Dobson, unpublished data). Estrous females might associate with many males in succession, accepting some as mating partners, or refusing others (e.g., when being chased in a burrow system a female could escape through another entrance). We terminated the focal female observation after she no longer accepted any male mating partner (i.e., she chased approaching males away), at which point she no longer actively searched for males and began extended bouts of feeding (Murie 1995).

During the mating sequence of each female, all consorting partners (see definition below) were identified by their dye markings, and we recorded three parameters for each male $i$ (all in minutes): (1) the consortship duration, (2) the mate guarding duration, and if the female mated with a subsequent male $j$ also (3) the interval (time from the end of mate guarding $i$, or consortship $i$ if there was no mate guarding occurred by $i$, to the next consortship by $j$ ). These parameters are presented in more detail below. The male's mating order ranged from one (first to mate) to a maximum of eight (termed "mating position" in Raveh et al. 2010). The time since the start of the mating sequence (in minutes) for male $i$ is defined as the time elapsed since the first male started consorting to the male $i$ starting consorting, so is always zero for the first male to mate and is the cumulative time spent in consort plus mate guarding plus interval of the males mating before male $i$.

Columbian ground squirrels usually mate underground, so copulation was not often observed directly. We thus refer to the time spent underground by the pair as "consortship duration". Nonetheless, consortship duration is likely to reflect true copulation duration, since (1) estrus occurs directly after hibernation, during that period females and males spend the maximum daylight period foraging and regaining body weight and entering a burrow together during daylight is otherwise rare (Manno et al. 2008); (2) males and females leaving the burrow show postcopulatory behaviors (i.e., male and female genital grooming, removal of copulatory plugs, mate guarding, and mate calling; Manno et al. 2007; Murie and McLean 1980; Murie 1995); and (3) paternity analysis revealed that males staying in a burrow for at least 15 min could sire offspring (Raveh et al. 2010). We sometimes missed recording consort duration, particularly for the first male to mate with the female, since the pair was not observed entering a burrow together (but we observed them emerging together; for more details, see Raveh et al. 2010). We assumed that underground copulations took place and defined "consortship" when an estrous female and a male were in the same burrow system for at least $5 \mathrm{~min}$. Otherwise we assumed no copulation occurred, and the event was discarded (Raveh et al. 2010). These criteria to establish copulation are similar to those used in similar species (e.g., Hanken and Sherman 1981; Hoogland and Foltz 1982; Lacey et al. 1997; Murie 1995).

Mate guarding duration was defined as the time spent by the male after consortship in chasing the female into a burrow, sitting on that burrow, and/or fighting with rival males to prevent and/or delay subsequent consortships (Manno et al. 2007).

The interval duration was defined as the time lag between two mating partners $(i$ and $j$ ). This was either the time from 
the termination of consortship by $i$ to the next consortship starting by $j$ (if the male $i$ did not guard the female) or the time from the termination of guarding by $i$ to the next consortship starting by $j$ (if the male $i$ did guard the female).

In total, complete mating sequence observations were acquired for mothers of 110 out of 147 litters, which we assumed to be an unbiased sample of all litters (i.e., the 110 litters showed similar patterns of siring success and number of sires as the complete sample of 147 litters; Raveh et al. 2010). The 110 litters excluded yearling females, who rarely reproduced successfully (Murie and Harris 1982; Festa-Bianchet and King 1984; Dobson and Murie 1987). Two consortships between the same male and female were observed in five out of 110 mating sequences but were retained in the analyses (they did not result in any offspring sired though we corrected for random male individual effects, see "Data analyses").

\section{After the mating event}

Nest burrows of gestating females were identified through behavioral observations (see Murie et al. 1998) and marked with colored flags. Females from three colonies were caught within 2 days of expected parturition and transported to a nearby field station. Females were housed indoors in polycarbonate cages $(48 \times 27 \times 20 \mathrm{~cm})$ enclosed in black covers (see Murie et al. 1998). The caged females were fed fresh lettuce and apple twice a day as well as a grain mixture (a molasses-enriched colt feed) provided ad libitum. Within $12 \mathrm{~h}$ from parturition, neonates were weighed, sexed, and a small amount of tissue was taken from the outer hind toe or the tail for subsequent DNA analysis $(N=147$ litters). Tissue samples were stored in 95\% EtOH and later used to determine paternity. Females and their litters were returned to the colonies the next day (for details, see Murie et al. 1998). In the fourth and fifth colonies, tissue for paternity analysis was collected from the ear at juvenile emergence (age 27 days). To standardize observations among all colonies, only offspring that successfully emerged from their nest burrows during weaning were included in subsequent analyses. Hence, we used presence at weaning as our measure of reproductive success. Offspring were caught within the first 2 days after emergence with either unbaited $13 \times 13 \times 40-\mathrm{cm}^{3}$ national live traps or with multi-capture traps (Murie et al. 1998). Juveniles were marked and weighed, and their sex was determined or confirmed if they were born in captivity.

\section{Operational sex ratio}

We recorded the daily operational sex ratio (OSR; Emlen and Oring 1977), which is the number of estrous females per number of active, adult males (at least 2 years old) per day during the mating season (calculated for each colony and year combination separately). Only 2-year or older males were used in OSR because yearling males were never observed to mate or sire offspring (Raveh et al. 2010). The OSR varied between 0.037 and 0.667 , which was due to the number of estrous females varying between 1 and 5 and the number of adult males varying between 1 and 29. The high variability in OSR was also due to (1) differences between colonies (Kruskal-Wallis test: $\chi^{2}=16.9, d f=4, p=$ 0.002 ), but not between years $\left(\chi^{2}=5.4, d f=3, p=0.14\right)$; (2) a peak of estrous females either early or in the middle of the mating season; and (3) differences in emergence dates after hibernation of both males and females for every colony and year combination. Nevertheless, in the majority of colony and year combinations (eight out of 11), the OSR was the highest and remained stable in the middle of the mating season (spanning 7 to 14 days). Note that both the number of estrous females and the number of adult males influenced the OSR (partial correlations with OSR controlling for the effect of the numbers of the other sex: effect of number of estrous females: $r_{\mathrm{p}}=0.25, N=115$ days, $p=0.006$; effect of number of adult males: $r_{\mathrm{p}}=-0.24, N=115$ days, $p=0.01$ ).

The variation in the number of males during the mating season was mainly influenced by the emergence dates of younger males (between 2 and 3 years old). Even though these 2- and 3-year-old males rarely defend a territory (Manno et al. 2007; Manno and Dobson 2008), they are still physically capable of obtaining copulations and siring success (Raveh et al. 2010).

\section{Paternity analysis}

Molecular methods for isolation of microsatellite loci and paternity assignment are provided in Raveh et al. (2010). Briefly, DNA was extracted from preserved tissue and amplified across 13 microsatellite loci (Goossens et al. 1998; Hanslik and Kruckenhauser 2000; Kyle et al. 2004; Stevens et al. 1997; Raveh et al. 2010) using polymerase chain reaction. Maternity was known for every offspring through isolation or behavioral observations (Raveh et al. 2010). Paternity was assigned at $95 \%$ to $99 \%$ confidence using CERVUS 3.0 (Marshall et al. 1998; Kalinowski et al. 2007) for each colony and each year (2005-2008) separately ( $N=110$ litters, for all 147 litters see Raveh et al. 2010).

\section{Data analyses}

Two different datasets were used for the analyses. First, the complete dataset contained 110 litters from 76 different females, where all offspring at weaning were successfully assigned to their respective sires and where we knew the mating order of each potential sire. Unfortunately we were not able to record the consort duration, mate guarding 
duration, or interval for each potential sire. Therefore, we created a second dataset containing 46 litters from 44 different females, which lacked only five values for male consort durations and six values for the interval (hereafter called the "selected dataset"). To complete the "selected dataset", these 11 missing values were implemented with the average values calculated for the respective mating order from the complete dataset: For consort duration $(N=5)$, this was done two times for order 2 and three times for order 3 , and for the interval between two consortships $(N=6)$, this was conducted two times for order 1 and four times for order 2. Note that we had no missing values for the mate guarding duration in the selected dataset. The selected dataset was used to analyze associations between sperm precedence and the underlying mechanisms in more detail.

All analyses were conducted in SPSS 17 (SPSS Inc., Chicago, IL, USA). We used generalized estimating equations (GEEs) in the majority of analyses, with individual male identifier as subject (which accounts for repeated measures per male), various canonical link functions depending on the parameter analyzed (normal distribution: identity link, Poisson distribution: log-link, weighted binomial distribution: logit link) and the scaling parameter estimated using the deviance method (Norusis 1994). The following independent variables were used throughout: year (2005 to 2008, fixed categorical effect), colony (A to E, fixed categorical effect), mating partners (two to eight, fixed categorical effect), and mating order (first to eighth, fixed continuous effect). Note that year and colony effects did not significantly influence the analyses ( $p$ between 0.50 and 0.99 ) and accordingly dropped from the final models for clarity. Male consort duration, mate guarding duration, and interval (all Poisson distributed) were analyzed using GEE with a log-link function. Siring success (offspring sired/litter size, logit link) was analyzed using GEE with consorting partners and mating order nested within mating partners as fixed effects and the relative consortship duration as a covariate (which is for the female mating with $n$ different males, the consortship duration of male $i$ divided by the total consortship duration of all males $n$ ). Note that the males' age (2-9 years old) had no significant effect on consort duration $(p=0.90)$, mate guarding duration $(p=0.94)$, or interval duration $(p=0.076$, the latter effect was negative when entered as a covariate into the models presented in Table 1). Likewise there were no effects of males' age on siring success ( $p=0.96$, see Table 2$)$ or on relative consort duration ( $p=0.75$, see Table 3$)$. Therefore, male age was removed from all models (Tables 1, 2, and 3).

Our dataset $(N=110$ litters) contained 50 individual females with one litter, 21 with two litters, two with three litters, and three with four litters. However, there were no correlations between the number of mating partners an individual female had in year $t$ compared to year $t+1$ (Pearson correlation, $r=0.263, p=0.13, N=34$ ), or between the degree of first-male siring success in year $t$ compared to year $t+1$ within these females $(r=-0.172, p=0.33, N=34)$. For that reason, we assume that individual female's number of mates was not consistent across years and that therefore the use of the same female more than once in the dataset did not bias analyses of behavioral correlates of paternity and male reproductive success.

\section{Results}

Paternity assignment

In total, 147 litters were successfully genotyped (113 females and 434 offspring and 95 potential male sires; Raveh et al. 2010). Out of these 434 offspring, 22 recruited in subsequent year(s) into the adult population (six males

Table 1 Male reproductive behavior depending on his mating order and the number of mating partners, corrected for year and colony effects

\begin{tabular}{|c|c|c|c|c|c|c|c|c|c|}
\hline \multirow[b]{2}{*}{ Parameter } & \multicolumn{3}{|c|}{ Consort duration ( $N=381$ of 69 males) } & \multicolumn{3}{|c|}{ Mate guarding duration $^{\mathrm{a}}$ ( $N=381$ of 67 males) } & \multicolumn{3}{|c|}{ Interval ( $N=298$ of 61 males) } \\
\hline & $d f$ & Wald $\chi^{2}$ & $p$ & $d f$ & Wald $\chi^{2}$ & $p$ & $d f$ & Wald $\chi^{2}$ & $p$ \\
\hline Intercept & 1 & $2,240.9$ & $<0.001$ & 1 & 227.8 & $<0.001$ & 1 & 83.3 & $<0.001$ \\
\hline Mating order & 7 & 74.511 & $<0.001$ & 4 & 62.6 & $<0.001$ & 6 & 26.8 & $<0.001$ \\
\hline Mating partners & 6 & 39.103 & $<0.001$ & 3 & 19.5 & $<0.001$ & 5 & 21.8 & 0.001 \\
\hline Year & 3 & 3.808 & 0.28 & 3 & 3.2 & 0.36 & 3 & 1.5 & 0.68 \\
\hline Colony & 4 & 25.552 & $<0.001$ & 4 & 2.2 & 0.69 & 4 & 10.0 & $<0.05$ \\
\hline
\end{tabular}

Durations (in minutes) were Poisson-distributed and modeled with a log-link using three separate GEEs, correcting for random individual male effects. Mating order was nested within the number of mating partners. The scaling parameter was adjusted using the deviance method. The interval is the duration from the end of guarding (or consortship when the male did not guard) to the next mating and is by default missing for the last male to mate

${ }^{a}$ Mate guarding was only performed by males consorting first to fifth in a mating sequence and virtually absent when the female mated with more than five partners, so the analysis was conducted for two to five mating partners only 
Table 2 Male siring success depending on his relative consort duration (duration/total consort duration by all males in the sequence), his mating order, and the interaction ( $N=185$ of 58 males)

\begin{tabular}{lcclc}
\hline Parameter & $d f$ & Wald $\chi^{2}$ & $p$ & Coefficient \pm SE \\
\hline Intercept & 1 & 1.1 & 0.29 & $-0.43 \pm 0.41$ \\
Relative consortship & 1 & 10.0 & 0.002 & $5.35 \pm 1.69$ \\
$\quad$ duration $C$ & & & & $-0.45 \pm 0.18$ \\
Mating order MO & 1 & 6.4 & 0.011 & $-1.94 \pm 0.95$ \\
$C \times$ MO & 1 & 4.1 & 0.042 & \\
\hline
\end{tabular}

Siring success had a weighted binomial distribution and was modeled with a logit-link using GEE, correcting for random individual male effects. The scaling parameter was adjusted using the deviance method. The number of mating partners (which correlates with both relative consortship duration and mating order), year, and colony effects were non-significant and removed from the model

and 16 females) and successfully reproduced, so the total number of unique genotypes was 95-6 males $+113-16$ females +434 offspring $=620$. Note that only reproductively active individuals and their offspring were genotyped, thereby excluding non-reproductive females and yearling males. Our genotyping success rate was $99 \%$, with $80 \%$ of the ground squirrels genotyped at all 13 loci $(N=620)$. We retained all 13 loci in our analyses as there was no significant deviation from Hardy-Weinberg equilibrium or linkage disequilibrium (Raveh et al. 2010). All 434 offspring were successfully assigned to both parents: $98 \%$ of the offspring had $99 \%$ trio-confidence, while the remaining $2 \%$ had $95 \%$ trio-confidence, suggesting that our sampling of adults was complete and any unsampled males were unlikely to be the true sires. In total, 412 offspring $(95.0 \%)$ had zero mismatches with both assigned parents, 21 offspring $(4.8 \%)$ had one mismatch with an assigned male or female parent, and one offspring had two mismatches with the known female parent. These two mismatches in the latter case were assumed to be mutations, as this specific female gave birth under controlled labora-

Table 3 Male relative consort duration (duration/total consort duration) depending on the time since the start of the mating sequence (in minutes, $0=$ first male started consorting), the number of mating partners, and their interaction ( $N=139$ of 53 males)

\begin{tabular}{llrll}
\hline Parameter & $d f$ & Wald $\chi^{2}$ & $p$ & Coefficient \pm SE \\
\hline Intercept & 1 & 148.5 & $<0.001$ & $-0.730 \pm 0.060$ \\
Time $T$ & 1 & 32.5 & $<0.001$ & $-0.001 \pm 0.0003$ \\
Mating partners MP & 1 & 55.8 & $<0.001$ & $-0.089 \pm 0.012$ \\
$T \times$ MP & 1 & 18.8 & $<0.001$ & $0.0002 \pm 0.00005$
\end{tabular}

Relative consort duration had a normal distribution and was modeled using GEE, correcting for random individual male effects. The scaling parameter was adjusted using the deviance method. The mating order (which correlates with the time in the sequence), year, and colony effects were non-significant and removed from the model tory conditions. See Raveh et al. (2010) for a more complete description of paternity assignment in the 147 litters and of the effects of mating order (first to eighth) and mating partners on siring success in the 110 litters (334 offspring) used for the subsequent analyses.

Mating order and siring success

Overall, male mating order had a strong effect on the male's siring success (Fig. 1; offspring genotyped in 110 litters: GEE with logit link, with $N=464$ consortships of 71 individual males entered as subjects; effect of male consorting order entered as a covariate: Wald $\chi^{2}=155.7$, $d f=1, p<0.001$; effects of year and colony were nonsignificant, both $p>0.9$, and omitted from the model). On average, males that consorted first sired around $60 \%$ of the offspring in the litter, and this proportion strongly declined to less than $5 \%$ in males mating fifth, whereas males mating sixth to eighth never sired any offspring. However, this first-male mating advantage declined significantly with the number of mating partners the female consorted with, which is analyzed and presented in more detail in Raveh et al. (2010). In the remaining part of this paper, we focus on the mechanisms which might have influenced these patterns of first-male precedence.

\section{Reproductive behavior}

Males consorted for $57.6 \pm 32.3 \mathrm{~min}( \pm \mathrm{SD}$, range $=8-261$, $N=381$ ) guarded females for $7.3 \pm 22.2 \mathrm{~min}$ (range $=0-223$, $N=464$ ), and the subsequent interval to a female's next consort was $23.9 \pm 28.9 \mathrm{~min}$ (range $=0-162, N=298$, measured from the end of consortship or guarding to the beginning of the next consort). Consortship and mate

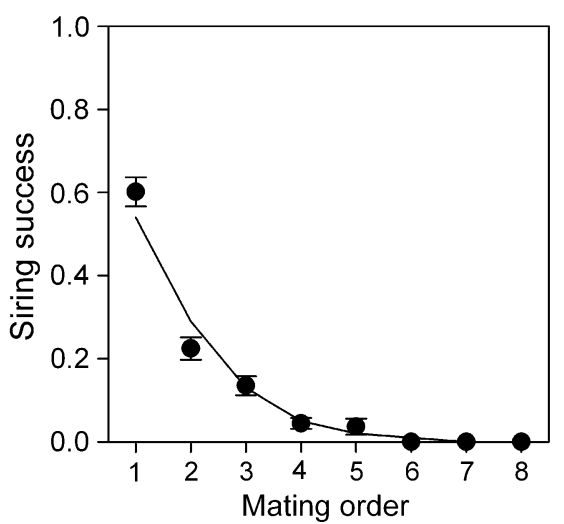

Fig. 1 First-male mating advantage in Columbian ground squirrels. Male siring success declined significantly with his mating order $(1=$ first to mate, $2=$ second to mate, etc.) and note that the sixth to the eighth male to mate never sired any offspring. See Raveh et al. (2010) for more details. Depicted are means \pm SEM, the weighted logistic regression line is from the GEE model in the main text (coefficient of mating order effect \pm SE $-1.028 \pm 0.082$, with intercept $1.177 \pm 0.1951$ ) 


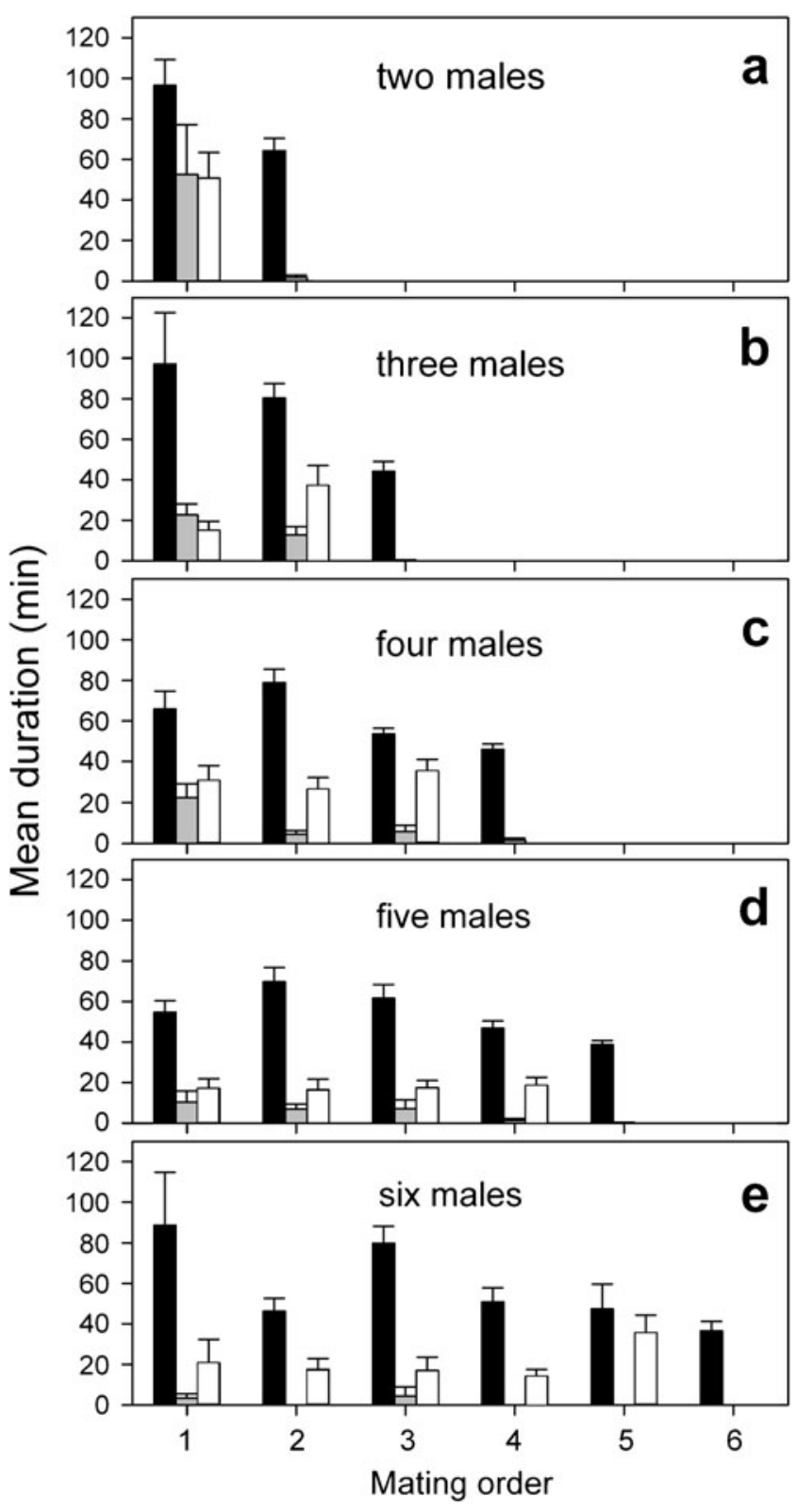

Fig. 2 Male reproductive behavior depending on his mating order and the number of males the female mated with a two males $(N=13$ litters), b three males $(N=48)$, c four males $(N=134$ litters), $\mathbf{d}$ five males ( $N=116$ litters), e six males ( $N=47$ litters; seven $N=18$ litters and eight $N=5$ litters omitted for clarity). Black bars: consorting duration, light-gray bars: mate guarding duration, white bars: interval to next male (means \pm SEM). Note that sample sizes varied per bar due to missing values. See Table 1 for statistical analyses

guarding duration decreased significantly with mating order and the number of mating partners (Fig. 2; Table 1). The interval to the next consortship increased with mating order and decreased with the number of mating partners (Fig. 2; Table 1). Male consortship and mate guarding duration were positively correlated, but the correlation coefficient was rather small (Spearman rank correlation $r_{\mathrm{s}}=0.24, N=381$, $p<0.001)$. Neither of these two behaviors were correlated with the interval duration $\left(r_{\mathrm{s}}=-0.06, N=354, p=0.35\right.$ and $r_{\mathrm{s}}=0.01, N=298, p=0.81$, respectively).

Mate guarding, OSR, and the number of consorting partners

The number of males each female consorted with was strongly influenced by (1) the mate guarding duration of the first male to mate and (2) the OSR (Poisson GEE with individual females as subjects, $\chi^{2}=7.1, d f=1, p=0.008$ and $\chi^{2}=5.1, d f=1, p=0.024$, respectively). Females consorted with less males when the first male guarded her for a prolonged period of time (coefficient \pm SE $-0.0023 \pm 0.0009$ from the above Poisson GEE). Additionally, females were less likely to consort with several partners when less males per estrous female were available (coefficient \pm SE $-0.41 \pm 0.18$ from the above Poisson GEE). The effect of the second males' guarding on the number of additional males was negative (i.e., potential third to eighth males consorting), but not significant (similar Poisson GEE as above, $p=0.077$ ), whereas the OSR remained significantly negative $(p=0.03)$.

Consortship behavior and siring success

The longest mating sequence lasted $546 \mathrm{~min}$ (from the start of the first until the end of the final consortship). The minimum consort duration that resulted in any sired offspring was $15 \mathrm{~min}$. In the selected dataset ( $N=46$ litters), male consortship duration and mating order both significantly affected siring success when tested separately (positive and negative, respectively, two GEEs, both $p<0.001$ ). Combining both factors and their interaction into one model (Table 2) showed that siring success declined with mating order, increased with the relative consortship duration, and depended on their interaction (Fig. 3). The interaction effect resulted in the relative consorting duration only affecting siring success positively for the first two males to consort (Fig. 3a, b), but not in later males to consort (Fig. 3c-e).

Timing within the mating sequence and siring success

The maximum time interval between two males successfully siring offspring was $345 \mathrm{~min}$ (ten out of 46 litters had values between 181 and $345 \mathrm{~min}$ ). In the selected dataset ( $N=46$ litters), male relative consort duration varied with the timing within the mating sequence, and this was independent of mating order (as can be seen from the mixture of mating orders in Fig. $4 \mathrm{~b}-\mathrm{e}$, see Table 3). The cumulative effects of previous males' behaviors on a focal male's siring success can thus be analyzed as a time-shift in the mating sequence (and so their average mating order), which causes these focal males to consort for a shorter time and gain less parentage. Indeed, the male's siring success could be entirely explained by this timing shift: Siring success 
Fig. 3 Male siring success (offspring sired/litter size) per mating order $(N=185$ consortships of 58 males) decreased with the relative consortship duration (duration/total consorting duration): a first; b second; c third; d fourth; and e fifth (circles), sixth (squares), and seventh (triangles) mating orders. Weighted logistic regression lines based on the model depicted in Table 2

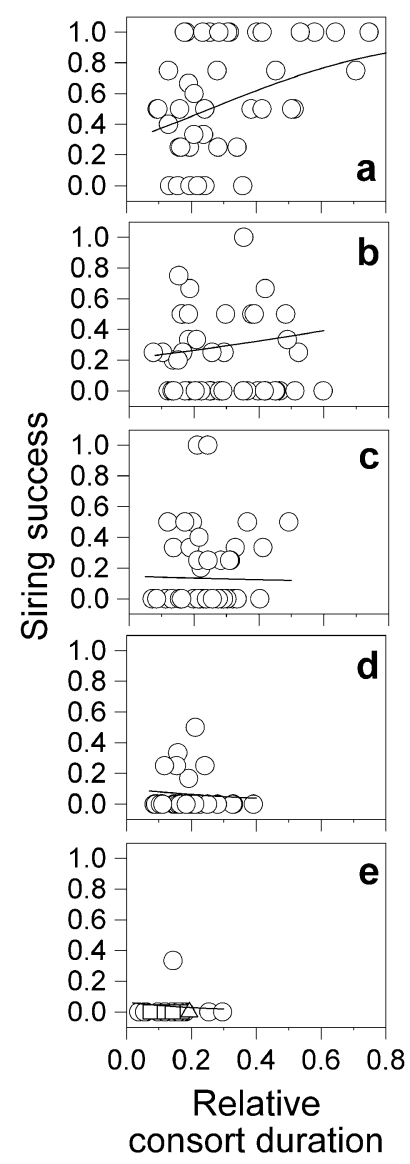

was negatively related to the amount of time passed since the start of the female's mating sequence (GEE, $\chi^{2}=10.5, d f=1$, $p=0.001$ ) and consequently was no longer related to the male's relative consort duration (if added to the above GEE: $\chi^{2}=0.5, d f=1, p=0.46$ ) nor related to the number of mating partners (if added to the above GEE, $\chi^{2}=0.8, d f=1, p=0.37$; $N=139$ of 53 males consorting second to eighth).

The timing in the mating sequence explained the pattern of siring success we initially attributed to mating order. A simple GEE model relating siring success (logit link) to lntransformed (time in the mating sequence +1 ) explained a large amount of variation in siring success (Fig. 5, $\chi^{2}=67.2$, $d f=1, p<0.001$; the corrected quasi-likelihood under independence model criterion was 855.6; with intercept $\pm \mathrm{SE}$ $0.258 \pm 0.227$ and slope \pm SE $-0.412 \pm 0.050, N=185$ of 58 males consorting first to eighth). Indeed, the pattern of siring success depicted in Fig. 5 closely matched the pattern of siring success in Fig. 1.

\section{Discussion}

In this study, we investigated alternative influences on firstmale precedence. Using a combination of mating observations and paternity analyses, we found that (1) the durations

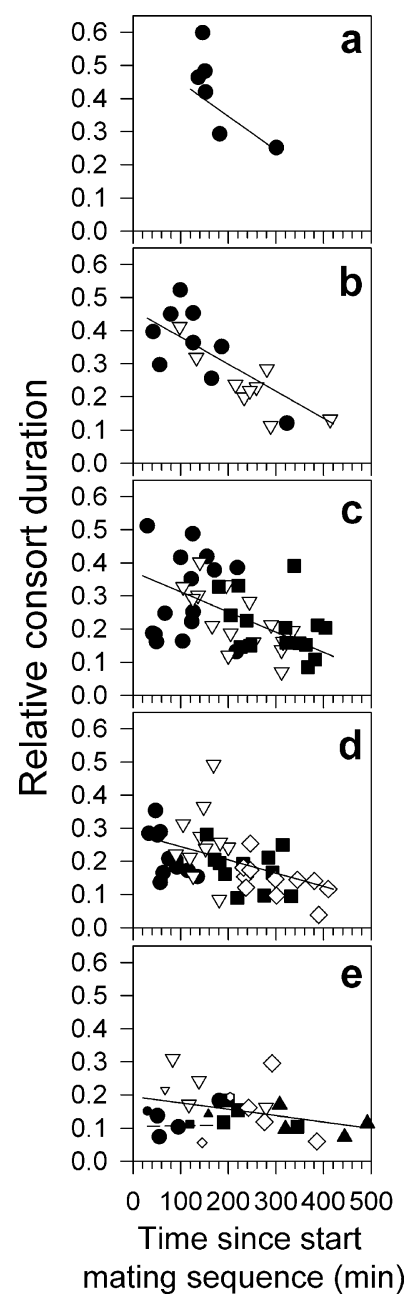

Fig. 4 Male relative consortship duration (duration/total consorting duration) decreased with the amount of time since the mating sequence started $(0=$ first male started consorting) and the number of mating partners (sample sizes and fitted lines from model in Table 3): a two, b three, c four, d five, and e six (large symbols, continuous line) and seven (small symbols, dotted line) males. Note that mating order had no effect (closed circles second, open triangles third, closed squares fourth, open diamonds fifth, closed triangles up sixth, and open circles seventh male in the mating order)

of male-female consortship and mate guarding decreased significantly with the male's mating order and the number of partners a female mated with, (2) the number of males a female consorted with was mainly influenced by first-male mate guarding behavior and the OSR, (3) male siring success significantly declined with order in the mating sequence and relative consort duration only affected siring success positively for the first two consortships within a mating sequence, and (4) male relative consort duration and siring success declined with the time passed since the female started to mate. The timing in the mating sequence seems to be a good predictor of the relative consort duration and therefore also a good predictor of actual siring success obtained. 


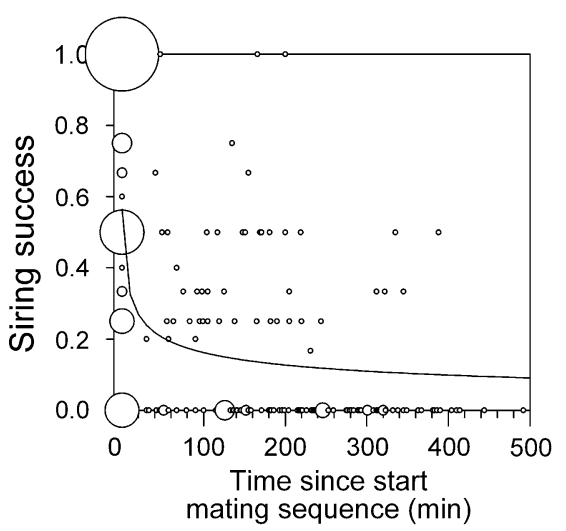

Fig. 5 The time since the mating sequence started $(0=$ first male started consorting) was closely related to the male's siring success, as it is a good predictor of the mating order, the number of mating partners the female eventually consorted with and how much each individual male invested in consorting. Fitted line from the GEE model presented in the text (logit-link siring success vs. In-transformed [time since start mating sequence +1 ]). $N=185$ consortships of 58 males, increasing symbol sizes denote increasing sample sizes (up to 15 overlapping data points)

We found that consortship and mate guarding durations decreased with increasing mating order, but these differences between mating orders decreased substantially when females mated with more than two males. Male siring success showed a positive relationship with relative consort duration, but only for males mating first or second. For the first male to mate, consortship duration significantly affected siring success. This was less true for the second male, and consortship durations of later mating males did not affect their siring success. Therefore, males can expect an increase in their siring success by (a) being the first male to mate with the female, when ideally only a few other potential mating partners are present, or otherwise (b) the first male should try to prolong the consortship and mate guarding to reduce the chances of paternity by other males. This could be beneficial in two ways: first by reducing the number of competitors (other males that mate with the female) and potentially forcing opponents into consortships that are less successful due to their timing relative to female receptivity.

The sperm precedence patterns found in our study species can, as yet, not be fully understood without knowing how consort duration (time spent underground) scales to actual copulation duration and sperm transfer. Calibrating the consort duration with the actual copulation duration (e.g., underground videotaping, see also Lisk et al. 1989) and the sperm transfer rates of males in the different mating orders should be done in the future to resolve this point. The shortest consort duration resulting in sired offspring that was observed in our study was $15 \mathrm{~min}$, which suggests that very short male-female associations may lead to successful sperm transfer in this species.
Male guarding behavior, OSR, and mating partners

In polygynandrous mating systems, post-copulatory behaviors may have a significant influence on sperm competition by limiting the ability of females to mate with additional males. In our study, mate guarding did not exclude multiple mating, as all successful reproductive females mated with a minimum of two males (first-time mating females occasionally have only one male partner; F.S. Dobson, unpublished data; these were not successful in our dataset). Nonetheless, mate guarding by the first male appeared to reduce the number of additional mates the female consorted with, which is in accordance with other studies (Martin 1984; Møller 1987; Hatchwell and Davies 1992; Alcock 1994; Johnsen et al. 1998; Zaldivar Rae and Drummond 2007). Mate guarding behavior that reduces the likelihood of additional mates supports the hypothesis that mate guarding plays a role in generating a first-male precedence.

Alternatively, the use of copulatory plugs in Columbian ground squirrels (Murie and McLean 1980) might be another male strategy to ensure paternity by assisting sperm transfer and blocking or delaying (if the plug is lost) a successful mating by a subsequent male (Gomendio et al. 1998). In general, these plugs do not appear to be effective in preventing further matings in mammals (see, e.g., Baumgardner et al. 1982; Dewsbury and Sawrey 1984; Gomendio et al. 1998; Koprowski 1992; Wolff and Sherman 2007). In our study population, some females were observed to pull out the plug after a consorting event; this removal may increase the interval to the next consortship. However, the majority of litters in our study are sired multiply (Raveh et al. 2010); therefore, copulatory plugs do not seem to be very effective in monopolizing fertilization success.

We found evidence that male-male competition for fertile females may determine the number of mating partners per litter (see review Kvarnemo and Ahnesjo 1996), but the effect appeared small. When the daily OSR was very high (ca. one estrous female per two males), females mated with fewer mating partners per litter (on average 3.75 males), as typical in the early mating season. When OSR was very low (ca. one estrous female per five males), which was typical in the middle of the mating season when the majority of males had emerged from hibernation, estrous females would mate with significantly more mating partners (on average 4.40 males). This suggests that (1) males are better at monopolizing estrous females when fewer competitors were present (Yamamura 1986; Clutton-Brock and Parker 1992; Shuster and Wade 2003), although the difference between these two extremes (4.40 vs. 3.75 ) was small, i.e., only 0.65 male partners or (2) that females are choosier when the sex ratio is highly male biased (since there are more males available to choose from). In the latter case, if high quality males are available 
throughout the whole mating season (e.g., because they emerge first and stay active through the whole season and if all females may prefer these males), the number of mating partners should decrease when more active males are around, contrary to what we found. Nevertheless, given that several females may be in estrus simultaneously on the same day, males may face a trade-off between the numbers of females they can mate with on the same day and the mating order they can achieve for each of these females.

Although females are assumed to play an active role in determining mate guarding duration (Jennions and Petrie 2000; Kokko and Morrell 2005), which may also hold true for Columbian ground squirrels females (which may or may not tolerate mate guarding; S. Raveh, P. Neuhaus, and F.S. Dobson, personal observation), our results rather suggest that male-male competition drives the relationship between OSR and the number of male mating partners, but again the effect appears small.

Consorting and mate guarding behavior in other ground squirrels

Studies on mating behavior in other ground squirrel species have shown that first-male precedence (as commonly found) may be influenced by male mating behavior and male competition over access to estrous females (Lacey et al. 1997; Waterman 2007). For instance, male Arctic ground squirrels and black tailed prairie dogs (Cynomys ludovicianus) can only increase their fertilization success by increasing their access to unmated females, since males mating second rarely sired any offspring (a ratio of about one of 11 cases; Lacey et al. 1997; Hoogland 1995). Conversely, male Belding's and 13-lined ground squirrels do not guard their females but instead search for the next female (scramble) in estrus directly after copulation and in which paternity is much more equitably shared among several males (Hanken and Sherman 1981; Schwagmeyer and Parker 1987; Sherman 1989).

Mate guarding is a costly post-copulatory behavior due to increased visibility to predators, energy invested in chasing females, fighting rival males, and missed mating opportunities with other partners (Pinxten and Eens 1997; Martín and López 1999; Komdeur 2001; Plaistow et al. 2003; Cothran 2004; Saeki et al. 2005). The resulting trade-off between mate guarding or searching for another female may end in a war of attrition (Parker 1979; Hammerstein and Parker 1982). Mate guarding by multiple males in sequence is found in other species (Clutton-Brock 1989; Birkhead and Møller 1992, 1998; Jormalainen 1998; Simmons 2001; Wolff and Sherman 2007). In Columbian ground squirrels, post-copulatory guarding behavior was not limited only to the first two males to consort, as in other species (Foltz and Schwagmeyer 1989;
Hoogland 1995; Lacey et al. 1997; Sherman 1989) but extended to the third and fourth mating partners, which seems to be quite unique. Our findings confirmed that males' investment in mate guarding declined throughout the mating sequence, which suggests that sperm from later mating males is progressively devalued due to mating behavior of the previous males. Previous paternity analyses revealed that up to the fifth consorting male are likely to sire offspring (Raveh et al. 2010); thus, guarding behavior seems to increase fertilization success. The cumulative effects of consorting and mate guarding durations of the previous males may have forced additional males to mate at a suboptimal time, e.g., outside of the optimal fertilization window of the female.

Compared to most species of ground-dwelling squirrels, $U$. columbianus had more mating partners (4.4. males per estrous female), which results in higher sperm competition. First-male precedence in Columbian ground squirrels seems to be enhanced by longer consortships and by suppressing the chances and investment of later mating males through mate guarding. The first five males within a mating sequence sired offspring, which is rather unusual in the Marmotini tribe. Female California ground squirrels (Otospermophilus beecheyi) mate with an average of 6.7 males on their day of estrus, and though $89 \%$ of litters are sired multiply, sperm precedence patterns remain elusive (Boellstorff et al. 1994). First-male precedence in Columbian ground squirrels is enhanced by longer consortships and by suppressing the chances and investment of later mating males through mate guarding. In Arctic ground squirrels, these differences in investment run in the opposite direction: The first male consorted for a shorter time than the second mating partner, but mate guarding was only performed by the first male and had no influence on siring success (Lacey et al. 1997). This could be an indication that Arctic ground squirrels have induced ovulation (Lacey et al. 1997). In the solitary 13-lined ground squirrel, which has a "scramble-competitive" mating system, the second male's fertilization success depends on the interval between copulations of the first and the second male and the duration of copulation achieved by the second male (Schwagmeyer and Parker 1987; Schwagmeyer and Foltz 1990). The different mating strategies found in ground squirrel species might be influenced by whether the particular species exhibits induced or spontaneous ovulation.

Currently, it is not known whether Columbian ground squirrels have induced or spontaneous ovulation. Only two studies on ovulation in ground squirrels are available: the solitary 13-lined ground squirrel I. tridecemlineatus (also tribe Marmotini) is thought to exhibit induced ovulation (Foster 1934), whereas the social Cape ground squirrel (Xerus inauris) has spontaneous ovulation (Bouchie et al. 
2006). Our study species might be a spontaneous ovulator, since this species re-cycles (which can take 5 to 10 days), when the first estrus did not result in successful consortships, for example due to adverse weather (F. S. Dobson, S. Raveh, and P. Neuhaus, unpublished data). Furthermore, induced ovulators typically have a very strong first-male advantage (Stevens et al. 1997; Soulsbury 2010), while Columbian ground squirrels can have a more even distribution of siring success. Future studies on species in the tribe Marmotini (including U. columbianus) should include mechanistic studies to establish whether a causal relationship between behavior and sperm precedence exists.

Acknowledgments We thank for help in the field E. Emery, C. Grossen, D. Karlen, C. Heiniger, N. Tonetti, K. Bieri, M. Berger, C. Deleglise, N. Brunner, M. Binggeli, and the M.Sc. students S. Röösli, B. M. Fairbanks, and A. Skiebiel. Thanks to E. Kubanek who assisted with genotyping. C. Saraux and R. Bergmüller helped with statistical analyses. R. Bshary, B. König, F. Trillmich, S. G. Kenyon, and J. E. Lane provided insightful comments on earlier drafts of this manuscript. The study was funded by a Swiss National Science Foundation grant to P. Neuhaus (SNF 3100AO-109816). D. Heg was supported by SNF grant 3100A0-108473, J.C. Gorrell by an Alberta Conservation Association Biodiversity grant, and F. S. Dobson by a US National Science Foundation research grant (DEB-0089473). The research was conducted under animal use protocols from the Biosciences Animal Care Committee, University of Alberta; the Life and Environmental Sciences Animal Resource Center, University of Calgary; and the Institutional Animal Care and Use Committee at Auburn University. The Institute of Biogeosciences (University of Calgary) provided housing and laboratory facilities at the R. B. Miller Field Station during the field season; we thank Station Manager J. Buchanan-Mappin, Institute Director E. Johnson, and camp responsible K. Ruckstuhl for their support.

\section{References}

Alcock J (1994) Postinsemination associations between males and females in insects: the mate guarding hypothesis. Annu Rev Entomol 39:1-21

Andersson M (1994) Sexual selection. Princeton University Press, Princeton

Baumgardner DJ, Hartung TG, Sawrey DK, Webster DG, Dewsbury DA (1982) Muroid copulatory plugs and female reproductive tracts: a comparative investigation. J Mammal 63:110-117

Birkhead TR, Møller AP (1992) Sperm competition in birds: evolutionary causes and consequences. Academic, London

Birkhead TR, Møller AP (1998) Sperm competition and sexual selection. Academic, London

Birkhead TR, Pizzari T (2002) Postcopulatory sexual selection. Nat Rev Genet 3:262-273

Boellstorff DE, Owings DH, Penedo MCT, Hersek MJ (1994) Reproductive behaviour and multiple paternity of California ground squirrels. Anim Behav 47:1057-1064

Bouchie L, Bennett NC, Jackson T, Waterman JM (2006) Are Cape ground squirrels (Xerus inauris) induced or spontaneous ovulators? J Mammal 87:60-66

Clutton-Brock TH (1989) Mammalian mating systems. Proc R Soc Lond B 236:339-372

Clutton-Brock TH, Parker GA (1992) Potential reproductive rates and the operation of sexual selection. Q Rev Biol 67:437-456
Cothran RD (2004) Precopulatory mate guarding affects predation risk in two freshwater amphipod species. Anim Behav 68:1133-1138

Danchin E, Giraldeau LA, Cezilly FC (2008) Behavioural ecology: an evolutionary perspective on behaviour. Oxford University Press, Oxford

Dewsbury DA, Sawrey DK (1984) Male capacity as related to sperm production, pregnancy initiation, and sperm competition in deer mice (Peromyscus maniculatus). Behav Ecol Sociobiol 16:37-47

Dobson FS (1983) Agonism and territoriality in the California ground squirrel. J Mammal 64:218-225

Dobson FS, Murie JO (1987) Interpretation of intraspecific life history patterns: evidence from Columbian ground squirrels. Am Nat 129(3):382-397

Dobson FS, Badry MJ, Geddes C (1992) Seasonal activity in the Columbian ground squirrel. Can J Zool 70:1364-1368

Emlen ST, Oring LW (1977) Ecology, sexual selection, and evolution of mating systems. Science 197:215-223

Festa-Bianchet M, King WJ (1984) Behavior and dispersal of yearling Columbian ground squirrels. Can J Zool 62:161-167

Foltz DW, Schwagmeyer PL (1989) Sperm competition in the thirteen-lined ground squirrel: differential fertilization success under field conditions. Am Nat 133:257-265

Foster MA (1934) The reproductive cycle in the female ground squirrel, Citellus tridecemlineatus (Mitchill). Am J Anat 54:487-511

Gomendio M, Harcourt AH, Roldàn ERS (1998) Sperm competition in mammals. In: Birkhead T, Møller AP (eds) Sperm competition and sexual selection. Academic, London, pp 667-755

Goossens B, Graziani L, Waits LP, Farand E, Magnolon S, Coulon J, Bel MC, Taberlet P, Allaine D (1998) Extra-pair paternity in the monogamous Alpine marmot revealed by nuclear DNA microsatellite analysis. Behav Ecol Sociobiol 43:281-288

Hammerstein P, Parker GA (1982) The asymmetric war of attrition. J Theor Biol 96:647-682

Hanken J, Sherman PW (1981) Multiple paternity in Belding's ground squirrel litters. Science 212:351-353

Hanslik S, Kruckenhauser L (2000) Microsatellite loci for two European sciurid species (Marmota marmota, Spermophilus citellus). Mol Ecol 9:2163-2165

Hatchwell BJ, Davies NB (1992) An experimental study of mating competition in monogamous and polyandrous dunnocks, Prunella modularis: I. Mate guarding and copulations. Anim Behav 43:595-609

Hoogland JL (1995) The black-tailed prairie dog: social life of a burrowing mammal. The University of Chicago Press, Chicago

Hoogland JL, Foltz DW (1982) Variation in male and female reproductive success in a harempolygynous mammal, the blacktailed prairie dog (Sciuridae: Cynomys ludovicianus). Behav Ecol Sociobiol 11:155-163

Jennions MD, Petrie M (2000) Why do females mate multiply? A review of the genetic benefits. Biol Rev Camb Philos Soc 75:21-64

Johnsen A, Lifjeld JT, Rohde PA, Primmer CR, Ellegren H (1998) Sexual conflict over fertilizations: female bluethroats escape male paternity guards. Behav Ecol Sociobiol 43:401-408

Jormalainen V (1998) Precopulatory mate guarding in crustaceans: male competitive strategy and intersexual conflict. Q Rev Biol 73:275-304

Kalinowski ST, Taper ML, Marshall TC (2007) Revising how the computer program CERVUS accommodates genotyping error increases success in paternity assignment. Mol Ecol 16:1099-1106

Koenig WD, Dickinson JL (2004) Ecology and evolution of cooperative breeding in birds. Cambridge University Press, Cambridge

Kohda M, Heg D, Makino Y, Takeyama T, Shibata J, Watanabe K, Munehara H, Hori M, Awata S (2009) Living on the wedge: female control of paternity in a cooperatively polyandrous cichlid. Proc R Soc Lond B 276:4207-4214 
Kokko H, Morrell LJ (2005) Mate guarding, male attractiveness and paternity under social monogamy. Behav Ecol 16:724-731

Komdeur J (2001) Mate guarding in the Seychelles warbler is energetically costly and adjusted to paternity risk. Proc R Soc Lond B 268:2103-2111

Koprowski JL (1992) Removal of copulatory plugs by female tree squirrels. J Mammal 73:572-576

Kraaijeveld-Smit FJL, Ward SJ, Temple-Smith PD, Paetkau D (2002) Factors influencing paternity success in Antechinus agilis: lastmale sperm precedence, timing of mating and genetic compatibility. J Evol Biol 15:100-107

Kvarnemo C, Ahnesjo I (1996) The dynamics of operational sex ratios and competition for mates. Trends Ecol Evol 11:404-408

Kyle CJ, Karels TJ, Clark B, Strobeck C, Hik DS, Davis CS (2004) Isolation and characterization of microsatellite markers in hoary marmots (Marmota caligata). Mol Ecol Notes 4:749-751

Lacey EA, Wieczorek JR, Tucker PK (1997) Male mating behaviour and patterns of sperm precedence in Arctic ground squirrels. Anim Behav 53:767-779

Lindén M, Moller AP (1989) Cost of reproduction and covariation of life history traits in birds. Trends Ecol Evol 4(12):367-371

Linn CD, Molina Y, Difatta J, Christenson TE (2007) The adaptive advantage of prolonged mating: a test of alternative hypotheses. Anim Behav 74:481-485

Lisk RD, Huck UW, Gore AC, Armstrong MX (1989) Mate choice, mate guarding and other mating tactics in golden hamsters maintained under semi-natural conditions. Behaviour 348:58-75

Manno TG, Dobson FS (2008) Why are male Columbian ground squirrels territorial? Ethology 114:1049-1060

Manno TG, Nesterova AP, Debarbieri LM, Kennedy SE, Wright KS, Dobson FS (2007) Why do male Columbian ground squirrels give a mating call? Anim Behav 74:1319-1327

Manno TG, DeBarbieri LM, Davidson J (2008) Why do Columbian ground squirrels copulate underground? J Mammal 89:882-888

Marshall TC, Slate J, Kruuk LEB, Pemberton JM (1998) Statistical confidence for likelihood-based paternity inference in natural populations. Mol Ecol 7:639-655

Martin K (1984) Reproductive defence priorities of male willow ptarmigan (Lagopus lagopus): enhancing mate survival or extending paternity options? Behav Ecol Sociobiol 16:57-63

Martín J, López P (1999) Nuptial coloration and mate guarding affect escape decisions of male lizards Psammodromus algirus. Ethology 105:439-447

Møller AP (1987) Mate guarding in the swallow Hirundo rustica. An experimental study. Behav Ecol Sociobiol 21:119-123

Murie JO (1995) Mating behavior of Columbian ground squirrels. 1. Multiple mating by females and multiple paternity. Can J Zool 73:1819-1926

Murie JO, Harris MA (1982) Annual variation of offspring emergence and breeding in Columbian ground squirrels (Spermophilus columbianus). J Mammal 63(3):431-439

Murie JO, McLean IG (1980) Copulatory plugs in ground squirrels. J Mammal 61:355-356

Murie JO, Stevens SD, Leoppky B (1998) Survival of captive-born cross-fostered juvenile Columbian ground squirrels in the field. $\mathrm{J}$ Mammal 79:1152-1160

Neuhaus P (2000) Timing of hibernation and molt in female Columbian ground squirrels. J Mammal 81:571-577
Neuhaus P, Pelletier N (2001) Mortality in relation to season, age, sex, and reproduction in Columbian ground squirrels (Spermophilus columbianus). Can J Zool 79:465-470

Norusis MJ (1994) SPSS graduate student statistical package (6.10). SPSS, Chicago

Oliveira R, Taborsky M, Brockmann HJ (2008) Alternative reproductive tactics: an integrative approach. Cambridge University Press, Cambridge

Parker GA (1970) Sperm competition and its evolutionary effect on copula duration in fly Scatophaga stercoraria. J Insect Physiol 16:1301-1328

Parker GA (1979) Sexual selection and sexual conflict. In: Blum MS, Blum NA (eds) Sexual selection and reproductive competition in insects. Academic, London, pp 123-166

Parker GA (1982) Why are there so many tiny sperm-sperm competition and the maintenance of 2 sexes. J Theor Biol 96:281-294

Parker GA (1984) Sperm competition and the evolution of animal mating systems. Academic, Orlando, pp 1-61

Pinxten R, Eens M (1997) Copulation and mate-guarding patterns in polygynous European starlings. Anim Behav 54:45-58

Pizzari T, Snook RR (2003) Perspective: sexual conflict and sexual selection: chasing away paradigm shifts. Evolution 57:1223-1236

Plaistow SJ, Bollache L, Cezilly F (2003) Energetically costly precopulatory mate guarding in the amphipod Gammarus pulex: causes and consequences. Anim Behav 65:683-691

Raveh S, Heg D, Dobson FS, Coltman DW, Gorrell JC, Balmer A, Neuhaus P (2010) Mating order and reproductive success in male Columbian ground squirrels (Urocitellus columbianus). Behav Ecol 21(3):537-547

Saeki Y, Kruse KC, Switzer PV (2005) Physiological costs of mate guarding in the Japanese beetle (Popillia japonica Newman). Ethology 111:863-877

Schwagmeyer PL, Foltz DW (1990) Factors affecting the outcome of sperm competition in thirteen-lined ground squirrels. Anim Behav 39:156-162

Schwagmeyer PL, Parker GA (1987) Queuing for mates in thirteen-lined ground squirrels. Anim Behav 35:1015-1025

Sherman PW (1989) Mate guarding as paternity insurance in Idaho ground squirrels. Nature 338:418-420

Shuster SM, Wade MJ (2003) Mating systems and strategies. Princeton University Press, Princeton

Simmons LW (2001) Sperm competition and its evolutionary consequences in the insects. Princeton University Press, Princeton

Soulsbury CD (2010) Ovulation mode modifies paternity monopolization in mammals. Biol Lett 6:39-41

Stevens S, Coffin J, Strobeck C (1997) Microsatellite loci in Columbian ground squirrels Spermophilus columbianus. Mol Ecol 6:493-495

Waterman JM (2007) Male mating strategies in rodents. In: Wolff JO, Sherman PW (eds) Rodent societies, an ecological and evolutionary perspective. University of Chicago Press, Chicago

Wolff JO, Sherman PW (2007) Rodent societies, an ecological and evolutionary perspective. University of Chicago Press, Chicago

Yamamura N (1986) An evolutionarily stable strategy (ESS) model of postcopulatory guarding in insects. Theor Popul Biol 29:438-455

Zaldivar Rae J, Drummond H (2007) Female accompaniment by male whiptail lizards: is it mate guarding? Behav 14:1383-1402 